\title{
Vicarious posttraumatic growth: A systematic literature review
}

\author{
Shekinah Manning-Jones $\cdot$ Ian de Terte $\cdot$ Christine Stephens
}

\begin{abstract}
Twenty-eight articles are included in this review, which provides the first comprehensive review of the vicarious posttraumatic growth (VPTG) literature. Five domains are presented. First, assessment methods of VPTG are reviewed; seventeen studies assessed VPTG using a measure designed for use with direct trauma survivors, three used a non-validated measure, and the remaining eight used an open-ended question. Second, the level of similarity between reports of direct and vicarious posttraumatic growth is examined. VPTG was found to be highly similar to direct posttraumatic growth; however, subtle differences between the two were also identified along with manifestations of growth unique to VPTG. Third, a range of psychological, cognitive, behavioural, interpersonal, and external factors that have been implicated to facilitate VPTG are presented. Fourth, research exploring the relationship between VPTG and secondary traumatic stress is examined. Three possible explanations are presented: a positive linear association, no association, and a more complex curvilinear relationship. Finally, limitations to the current body of knowledge and areas for future research are explored.
\end{abstract}

Keywords: vicarious posttraumatic growth, vicarious traumatic exposure, review

\section{Overview}

Posttraumatic growth can be characterised as positive cognitive, emotional, interpersonal and spiritual consequences that one may experience following a traumatic event (Tedeschi \& Calhoun, 2004). Posttraumatic growth occurs across three domains: self-perception, interpersonal relationships, and life philosophy (Tedeschi \& Calhoun, 1996). Specifically, Tedeschi and Calhoun (1996) argue that growth can occur in five distinct ways: an improvement in relating to others, greater personal strength, positive spiritual change, a greater appreciation of life, and discovering new possibilities. Vicarious posttraumatic growth (VPTG) refers to the development of these positive changes as a result of vicarious traumatic exposure (Arnold, Calhoun, Tedeschi, \& Cann, 2005). The term vicarious traumatic exposure has been used in the literature to refer to indirect traumatic exposure, for example exposure to direct trauma survivors and/or the aversive details of a traumatic event, rather than exposure to a traumatic event itself (e.g., Brockhouse, Msetfi, Cohen \& Joseph, 2011). A growing body of literature documents VPTG among health professionals (e.g., Shiri, Wexler, Alkalay, Meiner, \& Kreitler, 2008a), interpreters (e.g., Splevins, Cohen, Joseph, Murray \& Bowley, 2010) and members of the public (e.g., Linley, Joseph, Cooper, Harris, \& Meyer, 2003); however, to date a comprehensive evaluation and review of the literature has not been conducted.

Posttraumatic growth has been positively associated with greater life satisfaction (Mols, Vingerhoets, Coebergh, \& van de Poll-Franse, 2009), happiness (Lelorian, Bonnaud-Antiqnac, \& 
Florin, 2010), and general psychological, physical, and emotional wellbeing (Wild \& Paivio, 2004). It is reasonable to assume that VPTG also results in such benefits, and therefore it is an area worthy of future research. In order to produce meaningful research, researchers must be aware of all previously published studies. While reviewing the literature, it was evident that this was often not the case. For example a study published in 2014 claimed only three previous VPTG articles could be identified (Hyatt-Burkhart, 2014). A systematic literature review can be used as a tool to identify current gaps in the literature, limitations, and areas in need of future research. To date, no such review for the VPTG literature has been published. Cohen and Collens (2013) attempted to provide a metasynthesis of the VPTG literature; however, their decision to include only qualitative literature and to simultaneously review vicarious traumatisation limits the applicability of their results. This review aims to organise and evaluate current literature in a way that will guide and encourage future research. It will provide health professionals with a comprehensive synthesis of literature relating to VPTG, and may have practical implications as to how they can further facilitate VPTG in their workplace.

Five domains of literature will be reviewed here, chosen for their likelihood to spur future research. These domains are:

1) The measurement of VPTG.

2) The level of similarity between vicarious and direct posttraumatic growth.

3) Facilitating factors of VPTG.

4) The relationship between VPTG and secondary traumatic stress.

5) Current limitations and directions for future research.

\subsection{Literature search strategies}

Combinations of the following search terms were entered into the literature databases Scopus, PsycINFO, and Psychology and Behavioural Sciences Collection: secondary, vicarious, indirect, along with posttraumatic, posttrauma*, trauma*, adversarial, stress-related, positive transformation, psychological and growth. Searches were repeated in Science Direct, but were limited to psychological articles published in 2014 in an attempt to identify articles not yet available on other databases. Searches took place over January and February 2014. Databases returned a combined total of 3144 unique articles. Abstracts that suggested a specific focus on VPTG or a synonymous concept (e.g., positive self-transformation, positive psychological change) were further reviewed.

\subsection{Inclusion criteria}

Articles were included for review if they: a) were printed in a peer-reviewed journal, b) were printed in English, c) reported original data, d) outlined a specific focus on VPTG (or a synonymous term), and e) were specifically concerned with vicarious traumatic exposure. Articles were excluded if they: a) referred to a shared reality between participants and direct trauma survivors, b) conducted research with emergency workers or with family members of direct trauma survivors (these individuals were deemed to have experienced direct rather than vicarious traumatic exposure), and c) were review or metasynthesis articles. This resulted in the identification of 24 relevant articles. Reference lists were evaluated using the same criteria, and four additional articles were selected. 
Table 1a. Summary of the 28 articles included in the current review

\begin{tabular}{|c|c|c|c|c|}
\hline Study & Participants & Methodology & Assessment method & $n$ \\
\hline $\begin{array}{l}\text { Arnold, Calhoun, Tedeschi, \& } \\
\text { Cann (2005) }\end{array}$ & Psychotherapists & $\begin{array}{l}\text { Qualitative: Naturalistic } \\
\text { interviews }\end{array}$ & $\begin{array}{l}\text { "How have you been affected by } \\
\text { your work with clients who have } \\
\text { experienced traumatic events?" }\end{array}$ & 21 \\
\hline $\begin{array}{l}\text { Barrington \& Shakespeare-Finch } \\
\text { (2013) }\end{array}$ & $\begin{array}{l}\text { Clinical and } \\
\text { administrative/ } \\
\text { managerial staff working } \\
\text { with refugees }\end{array}$ & $\begin{array}{l}\text { Qualitative: Semi- } \\
\text { structured interviews }\end{array}$ & Open-ended question & 17 \\
\hline Ben-Porat \& Itzhaky (2009) & Social workers & Quantitative: Survey & PTGI & 214 \\
\hline Bentar $(2000)$ & Therapists & $\begin{array}{l}\text { Qualitative: Open ended } \\
\text { in-depth interviews }\end{array}$ & Open-ended question & 12 \\
\hline $\begin{array}{l}\text { Brockhouse, Msetfi, Cohen, \& } \\
\text { Joseph (2011) }\end{array}$ & Therapists & Quantitative: Survey & PTGI & 118 \\
\hline Davis \& Macdonald (2004) & $\begin{array}{l}\text { General Canadian } \\
\text { population }\end{array}$ & $\begin{array}{l}\text { Quantitative: Structured } \\
\text { interview }\end{array}$ & $\begin{array}{l}\text { Using a 4-point scale, } \\
\text { participants rated the extent to } \\
\text { which they felt the event } \\
\text { changed: (i) their relationship } \\
\text { with family; (ii) their } \\
\text { relationship with friends; and } \\
\text { (iii) their values. }\end{array}$ & 80 \\
\hline $\begin{array}{l}\text { Gibbons, Murphy, \& Joseph } \\
\text { (2011) }\end{array}$ & Social workers & $\begin{array}{l}\text { Quantitative: } \\
\text { Survey }\end{array}$ & $\begin{array}{l}\text { PTGI } \\
\text { CiOQ }\end{array}$ & 62 \\
\hline Guhan \& Liebling-Kalifani (2011) & Support workers & $\begin{array}{l}\text { Mixed Methods: } \\
\text { Qualitative semi- } \\
\text { structured interviews and } \\
\text { quantitative self-report } \\
\text { questionnaire }\end{array}$ & Open-ended question & 12 \\
\hline
\end{tabular}


Table $1 \mathrm{~b}$. Summary of the 28 articles included in the current review

\begin{tabular}{|c|c|c|c|c|}
\hline Study & Participants & Methodology & Assessment method & $n$ \\
\hline Hyatt-Burkhart (2014) & Mental health workers & $\begin{array}{l}\text { Qualitative: Semi- } \\
\text { structured interviews and } \\
\text { focus groups }\end{array}$ & $\begin{array}{l}\text { "How have you been affected by } \\
\text { your work with children who } \\
\text { have experienced traumatic } \\
\text { events?" }\end{array}$ & 12 \\
\hline $\begin{array}{l}\text { Kjellenberg, Nilsson, Daukantaité, } \\
\text { \& Cardeña (2014) }\end{array}$ & $\begin{array}{l}\text { Professionals working } \\
\text { with war and torture } \\
\text { survivors }\end{array}$ & Quantitative: Survey & PTGI & 69 \\
\hline Lambert \& Lawson (2013) & Counsellors & Quantitative: Survey & PTGI & 125 \\
\hline Linley \& Joseph (2005) & Funeral directors & Quantitative: Survey & CiOQ & 78 \\
\hline \multirow[t]{2}{*}{ Linley \& Joseph (2007) } & \multirow[t]{2}{*}{ Therapists } & \multirow{2}{*}{ Quantitative: Survey } & PTGI-SF & \multirow[t]{2}{*}{156} \\
\hline & & & CiOQ & \\
\hline \multirow{2}{*}{$\begin{array}{l}\text { Linley, Joseph, Cooper, Harris, \& } \\
\text { Meyer (2003) }\end{array}$} & \multirow{2}{*}{$\begin{array}{l}\text { General British } \\
\text { population }\end{array}$} & \multirow[t]{2}{*}{ Quantitative: Survey } & PTGI & \multirow[t]{2}{*}{108} \\
\hline & & & $\mathrm{CiOQ}$ & \\
\hline \multirow[t]{2}{*}{ Linley, Joseph, \& Loumidis (2005) } & \multirow[t]{2}{*}{ Therapists } & \multirow[t]{2}{*}{ Quantitative: Survey } & PTGI & \multirow[t]{2}{*}{85} \\
\hline & & & CiOQ & \\
\hline O'Sullivan \& Whelan (2011) & Telephone counsellors & Quantitative: Survey & PTGI & 64 \\
\hline Samios, Rodzik, \& Abel (2012) & Therapists & Quantitative: Survey & PTGI & 61 \\
\hline $\begin{array}{l}\text { Satkunanayagam, Tunariu, \& } \\
\text { Tribe (2010) }\end{array}$ & $\begin{array}{l}\text { Mental health } \\
\text { professionals }\end{array}$ & $\begin{array}{l}\text { Qualitative: Semi- } \\
\text { structured interviews }\end{array}$ & Open-ended question & 12 \\
\hline Shamai \& Ron (2009) & Social workers & $\begin{array}{l}\text { Qualitative: Semi- } \\
\text { structured interviews }\end{array}$ & Open-ended question & 29 \\
\hline \multirow[t]{2}{*}{ Shiri, Wexler, \& Kreitler (2010) } & \multirow{2}{*}{$\begin{array}{l}\text { Nurses and rehabilitation } \\
\text { teams }\end{array}$} & Mixed methods: & \multirow[t]{2}{*}{ PTGI } & \multirow[t]{2}{*}{$68^{*}$} \\
\hline & & $\begin{array}{l}\text { Qualitative interview and } \\
\text { quantitative survey }\end{array}$ & & \\
\hline
\end{tabular}


Table 1c. Summary of the 28 articles included in the current review

\begin{tabular}{|c|c|c|c|c|}
\hline Study & Participants & Methodology & Assessment method & $n$ \\
\hline $\begin{array}{l}\text { Shiri, Wexler, Alkalay, Meiner, \& } \\
\text { Kreitler (2008a) }\end{array}$ & $\begin{array}{l}\text { Doctors, therapists and } \\
\text { nurses }\end{array}$ & Quantitative: Survey & PTGI & 138 \\
\hline $\begin{array}{l}\text { Shiri, Wexler, Alkalay, Meiner, \& } \\
\text { Kreitler (2008b) }\end{array}$ & $\begin{array}{l}\text { Hospital rehabilitation } \\
\text { workers }\end{array}$ & Quantitative: Survey & PTGI & $31^{*}$ \\
\hline $\begin{array}{l}\text { Splevins, Cohen, Joseph, Murray, } \\
\text { \& Bowley (2010) }\end{array}$ & Interpreters & $\begin{array}{l}\text { Qualitative: Semi- } \\
\text { structured interview }\end{array}$ & $\begin{array}{l}\text { Open-ended question } \\
\text { e.g., "I'm wondering what it's } \\
\text { like for you to listen to your } \\
\text { client's stories." }\end{array}$ & 8 \\
\hline $\begin{array}{l}\text { Swickert, Hittner, DeRoma, \& } \\
\text { Saylor (2006) }\end{array}$ & $\begin{array}{l}\text { General American } \\
\text { population }\end{array}$ & Quantitative: Survey & PBS & 136 \\
\hline Taku (2014) & Physicians & Quantitative: Survey & PTGI- Short Form & 289 \\
\hline $\begin{array}{l}\text { Taubman-Ben-Ari \& Weintroub } \\
\text { (2008) }\end{array}$ & Physicians and nurses & Quantitative: Survey & PTGI & 124 \\
\hline Tehrani (2007) & Care workers & Quantitative: Survey & Trauma Belief Inventory & 430 \\
\hline Tehrani (2010) & $\begin{array}{l}\text { Occupational health } \\
\text { advisors, Human } \\
\text { resource advisors, } \\
\text { Counsellors, Family } \\
\text { Liaison officers }\end{array}$ & Quantitative: Survey & Carer Belief Inventory & 276 \\
\hline
\end{tabular}

\footnotetext{
* Sample size reflects the number of participants who fit the criteria to be included in this review.
} 


\subsection{Selected articles}

Of the 28 articles identified for review, 19 were quantitative, seven qualitative, and two utilised mixed methods. Twenty-five articles conducted research with professionals who experienced vicarious traumatic exposure through their work, for example health professionals, funeral directors, and interpreters. Together, these professionals had been vicariously exposed to a wide range of traumatic events such as war, domestic violence, sexual assault, and the Holocaust. The remaining three articles focused on the general population who had vicariously been exposed to the September 11 terrorist attacks. Table 1 above provides an overview of the included articles.

\section{Measurement of Vicarious Posttraumatic Growth}

Currently, there is no measure designed specifically to assess VPTG; therefore, all quantitative studies used a measure originally designed for direct trauma survivors. Seventeen articles assessed VPTG using a validated measure of posttraumatic growth. Eleven articles used a version of the Posttraumatic Growth Inventory (PTGI; Tedeschi \& Calhoun, 1996), one used the Positive Changes subscale of the Changes in Outlook Questionnaire (CiOQ; Joseph, Williams, \& Yule, 1993), four used the PTGI and CiOQ in combination, and one used the Perceived Benefit Scale (PBS; McMillen \& Fisher, 1998). These self-report questionnaires required participants to rate their level of agreement with statements describing various psychological and behavioural changes that can follow traumatic exposure.

Three studies measured VPTG with non-validated instruments. Davis and Macdonald (2004) measured VPTG using a structured interview; they asked participants to rate the extent to which they had experienced positive change in their relationships and personal values on a 4-point scale. If participants had experienced positive change, follow-up questions on the nature of this change were administered. Tehrani $(2007,2010)$ measured VPTG using four items (see Table 1 above) originally targeted at assessing positive beliefs. While Tehrani (2007) argued that these items were consistent with the personal strength and appreciation of life subscales of the PTGI, a lack of evidence of convergent validity means results should be interpreted with caution.

The remaining eight studies assessed VPTG using qualitative methods. Non-specific openended questions were used to enquire about the impact of vicarious traumatic exposure generally, for example "How have you been affected by your work with clients who have experienced a traumatic event?" (Arnold et al., 2005, p. 245). Specific follow-up questions were administered if descriptions of VPTG were not spontaneously given. If provided, qualitative questions are presented in Table 1 above.

\section{Vicarious and direct posttraumatic growth}

From the reviewed articles it was evident that aspects of VPTG are consistent with conceptualisations of posttraumatic growth among direct trauma survivors. Professionals working with refugees experienced changes in their values and priorities, spiritual growth, greater personal strength, and enhanced interpersonal relationships (Barrington \& ShakespeareFinch, 2013), all consistent with Tedeschi and Calhoun's (1996) conceptualisation of direct posttraumatic growth. Similar changes were noted among psychotherapists (Arnold et al., 2005), social workers (Shamai \& Ron, 2009), interpreters (Splevins et al., 2010), and support workers (Guhan \& Liebling-Kalifani, 2011).

However, subtle differences were also apparent between these two forms of psychological growth. For example, participants reporting VPTG reflected upon the resiliency of mankind in general (Arnold et al., 2005; Splevins et al., 2010), which is more abstract than the sense of 
increased personal strength generally reported by direct trauma survivors (e.g., Hefferon, Grealy, \& Mutrie, 2009). In addition, while direct trauma survivors often report personal spiritual growth, therapists reported a type of spiritual broadening, referring to the acceptance of spiritual beliefs as a helpful healing tool following trauma, without experiencing any personal belief changes (Arnold et al., 2005). Therefore, VPTG appears to differ slightly from direct posttraumatic growth; perhaps it is less integrated with a person's self-concept.

In addition, there were aspects of growth unique to VPTG, largely concerning professional identity. Participants spoke of the realisation that their work was valuable, that they had the ability to make a difference in the lives of direct trauma survivors, and that their experience had enhanced their professional capabilities (Barrington \& Shakespeare-Finch, 2013; Guhan \& Liebling-Kalifani, 2011; Bentar, 2000; Satkunanayagam, Tunariu, \& Tribe, 2010; Shamai \& Ron, 2009; Splevins et al., 2010). Overall, VPTG made participants feel more competent in their workplace. This likely reflects the context of participants' vicarious traumatic exposure.

Overall, it appears that direct and vicarious posttraumatic growth are highly similar. However, there are also subtle differences between the two and even manifestations of growth that are unique to VPTG, distinguishing the two constructs and representing their differing origins. VPTG could be considered to fall under the larger "umbrella" of posttraumatic growth, but should also be seen as a distinct concept that differs from direct posttraumatic growth in ways that will have important implications for the way it is reported and assessed.

\section{Factors that facilitate the development of VPTG}

A range of factors that facilitate the development of VPTG were identified from the 28 reviewed articles. These are discussed below within the following categories: cognitive and psychological, behavioural, interpersonal, and external variables.

\subsection{Cognitive and psychological variables}

Empathetic engagement was identified as an important factor in the development of VPTG. Several articles reported a positive association between these two variables (Brockhouse et al., 2011; Linley \& Joseph, 2007), and qualitative studies described how experiencing empathy for direct survivors spurred participants' own psychological growth (Shamai \& Ron, 2009; Splevins et al., 2010). It appears that empathetic engagement enables helping professionals to metaphorically apply the traumatic event to their own lives, facilitating VPTG (Linley \& Joseph, 2007; Shamai \& Ron, 2009; Splevins et al., 2010). However, no relationship was found between empathy and VPTG among telephone counsellors (O'Sullivan \& Whelan, 2011) or those vicariously exposed to the September 11 terrorist attacks (Davis \& Macdonald, 2004). One possible explanation is that empathy is positively associated with VPTG only when it exceeds a certain level; studies that reported a positive relationship between empathy and VPTG also reported higher levels of empathy than those that reported no significant relationship (Brockhouse et al., 2011; Linley \& Joseph, 2007; O'Sullivan \& Whelan, 2011). Alternatively, perhaps telephone counsellors and those exposed to the September 11 terrorist attacks via the media felt limited in their capacity to help the direct trauma survivors. This may have acted as a moderating variable on the relationship between empathy and VPTG, reducing the positive association. Further research is needed to ascertain the nature of the relationship between empathy and VPTG.

Optimism and positive affect were also identified as factors conducive to VPTG. Having positive and optimistic beliefs about the future and about the benefits of suffering was positively associated with aspects of VPTG among nurses and rehabilitation workers (Shiri, Wexler, \& 
Kreitler, 2010). Linley and Joseph (2005) reported that those funeral directors with the highest levels of positive affect also reported the greatest levels of VPTG. It may be that positive affect and optimism facilitate the identification of positive outcomes following vicarious traumatic exposure.

In contrast, negative affect was also found to be a salutary factor. Among their sample of funeral workers, Linley and Joseph (2005) found negative affect to positively correlate with VPTG. This likely reflects the fact that it is necessary to experience devastation and distress following vicarious traumatic exposure before one is able to develop VPTG (Davis \& Macdonald, 2004). The reality that one must experience the negative psychological effects of vicarious traumatic exposure before VPTG is possible (Davis \& Macdonald, 2004) is consistent with the finding that VPTG is related to both negative and positive affect.

Having a sense of satisfaction, competence, and value in one's work was found to enhance VPTG. Among nurses and physicians, professional self-esteem, defined as the extent to which professionals perceived themselves to be professionally competent and valuable (Carmel, 1997), was positively associated with VPTG (Taubman-Ben-Ari \& Weintroub, 2008). In addition, compassion satisfaction, defined as a sense of pleasure or satisfaction gained from one's job (Stamm, 2005), and self-perceived value of one's work were positively associated with VPTG among social workers (Gibbons, Murphy, \& Joseph, 2011). However, this was not the case among professionals working with war and torture survivors, despite similar levels of compassion satisfaction being recorded (Kjellenberg, Nilsson, Daukantaité, \& Cardeña, 2014). The reason for these divergent results is unclear. Perhaps working with war and torture survivors was so far removed from the reality of the participants' personal lives that their work, and the satisfaction they got from this, did not transcend into positive personal changes. In contrast, the social workers included in Gibbon et al.'s (2011) sample may have experienced a greater level of identification with their clients, and therefore the satisfaction they got from their work related to positive personal growth. Further research is needed to investigate this hypothesis.

Mixed results have been reported regarding the relationship between having a strong sense of coherence, defined as "the extent to which the world is seen as comprehensible, manageable, and meaningful" (Brockhouse et al., 2011, p. 736) and posttraumatic growth. Linley, Joseph, and Loumidis (2005) reported this construct to be positively associated with VTPG; however, this was the case only when using the CiOQ: research has not found a positive relationship between sense of coherence and VPTG when utilising the PTGI (Linley \& Joseph, 2007; Linley et al., 2005; Samios, Rodzik, \& Abel, 2012). In fact, one study found having a strong sense of coherence to negatively predict VPTG, perhaps because it enhances resiliency which in turn reduces opportunity for growth (Brockhouse et al., 2011). Overall, the majority of reviewed studies did not support a positive association between sense of coherence and VPTG; however, more research is needed in this area to provide an accurate picture of the relationship between these two constructs.

Among therapists, theoretical orientation was identified as an important factor relating to VPTG. In regards to both therapeutic training and practice orientation, Linley and Joseph (2007) reported that humanistic and transpersonal orientations were positively associated with VPTG, while cognitive-behavioural training was negatively associated. Linley and Joseph suggest that this likely reflects the philosophy of humanistic and transpersonal therapies, which acknowledge that suffering can provide opportunities for growth and development. They also suggest that therapists who practise cognitive-behavioural therapy are more likely to work with severe client populations, which may reduce opportunities for VPTG. Further research is needed to explore 
whether such findings can be replicated and also to elucidate the different relationships between therapeutic intervention and VPTG outcomes.

Finally, there were contradictory findings regarding the relationship between resilience and VPTG. Resilience was positively associated with VPTG among physicians (Taku, 2014); however, beliefs about resilience (e.g., how much participants believed that difficulties can be perceived as challenges to be overcome) negatively predicted the identification of new possibilities, a domain of VPTG, among nurses and rehabilitation workers (Shiri et al., 2010). Perhaps individuals who hold such beliefs about resilience have a positive attitude that enables them to cope in the face of adversity, but that also reduces their opportunity for VPTG by minimising the initial impact of the vicarious traumatic exposure. The investigation of resilience itself is a complex area (Windle, 2011); its role in VPTG would be a fruitful area for further investigation.

\subsection{Behavioural variables}

Many of the studies reviewed supported a positive association between engaging in self-care activities and VPTG (Arnold et al., 2005; Barrington \& Shakespeare-Finch, 2013; Satkunanayagam et al., 2010; Splevins et al., 2010; Tehrani, 2010). Only one study reported that it did not find a significant positive relationship between self-care and VPTG (Lambert \& Lawson, 2013), and this study reported little information on how self-care was defined or assessed. Common self-care activities cited in the studies reviewed include exercise, healthy eating, engaging in hobbies, prayer, and spiritual and religious activities (Arnold et al., 2005; Barrington \& ShakespeareFinch, 2013; Satkunanayagam et al., 2010; Splevins et al., 2010; Tehrani, 2010). Splevins et al. (2010) argued that self-care activities were active and conscious coping strategies utilised by participants to reduce psychological distress and protect their wellbeing. This process appears to facilitate the development of VPTG.

Personal therapy was also found to enhance the likelihood of experiencing VPTG. Therapists who engaged in personal therapy reported greater levels of VPTG than was reported by those who did not (Brockhouse et al., 2011; Linley \& Joseph, 2007). Linley and Joseph (2007) argued that this demonstrates the ability of personal therapy not only to decrease distress, but also to facilitate positive changes and personal growth. It is possible that therapy provides the opportunity to process and find meaning in vicarious traumatic exposure. Future research should investigate whether these findings are replicated in other samples.

\subsection{Interpersonal variables}

Social support, in particular supervision and peer support, has been linked with the development of VPTG (Brockhouse et al., 2011; Linley \& Joseph, 2005, 2007; Satkunanayagam et al., 2010; Tehrani, 2010). Such findings are consistent with influential models of posttraumatic growth (Schaefer \& Moos, 1998; Tedeschi \& Calhoun, 2004) which suggest that social support positively influences coping and adaption following trauma, improves social resources, and decreases isolation and loneliness, all facilitating posttraumatic growth. Other forms of social support, such as organisational support (Brockhouse et al., 2011) and talking to family or friends (Tehrani, 2010), were not found to facilitate growth. It appears that on-going supervision and peer support are the most beneficial forms of social support following vicarious traumatic exposure.

Witnessing posttraumatic growth in direct trauma survivors was identified as a facilitative factor of VPTG. Professionals working with refugees (Barrington \& Shakespeare-Finch, 2013), psychotherapists (Arnold et al., 2005), interpreters (Splevins et al., 2010), and support workers (Guhan \& Liebling-Kalifani, 2011) all described how witnessing growth in their clients helped them to develop their own personal growth. Witnessing growth among survivors caused 
participants to become shocked and amazed at the strength of human resiliency and triggered positive emotions such as hope, joy, and happiness (Splevins et al., 2010), which facilitated the process of VPTG.

\subsection{External variables}

Time was identified as one external factor that may facilitate the development of VPTG. Helping professionals working with refugees (Barrington \& Shakespeare-Finch, 2013), interpreters (Splevins et al., 2010), and social workers (Shamai \& Ron, 2009) reported that over time their levels of distress decreased and were replaced by personal growth. This may suggest a temporal sequence to the psychological outcome of vicarious traumatic exposure: perhaps it is natural for professionals to react initially with distress, but over time they are able to process and find meaning in the event, resulting in VPTG.

Finally, there are mixed results regarding whether having a personal trauma history facilitates VPTG following subsequent vicarious traumatic exposure. Three studies reported a positive association between VPTG and personal trauma history (Kjelleberg et al., 2014; Linley \& Joseph, 2007; Swickert, et al., 2006); however, one study reported no difference in VPTG levels between those participants with a personal trauma history and those without. Perhaps the way previous traumatic events were processed influences whether or not they facilitate VPTG following subsequent vicarious traumatic exposure (Schaefer \& Moos, 1998). However, results should be interpreted with caution because it is unclear whether personal trauma history had been controlled for when measuring VPTG; therefore the posttraumatic growth recorded may have resulted from the participant's own personal trauma, rather than their vicarious traumatic exposure.

\section{Vicarious posttraumatic growth and secondary traumatic stress}

Secondary traumatic stress refers to the presence of symptoms typically displayed by individuals suffering from Posttraumatic Stress Disorder, but which result from vicarious rather than direct traumatic exposure (Canfield, 2005). Symptoms such as intrusive thoughts or flashbacks to the vicarious trauma, avoidance of related stimuli, hyperarousal, and negative changes to cognition and mood have been reported (e.g., Steed \& Downing, 1998). Based on this description, it could be assumed that secondary traumatic stress and VPTG represent opposite ends of the same continuum; on one end are the positive effects of vicarious traumatic exposure and on the other end the negative effects. In contrast, several studies included in this review reported a positive association between VPTG and secondary traumatic stress (e.g., Davis \& Macdonald, 2004; Kjellenberg et al., 2014). One explanation of these results may be that, prior to experiencing VPTG, individuals experience initial shock, devastation, and the shattering of their assumptions about themselves and the world (O'Sullivan \& Whelan, 2011; Shamai \& Ron, 2009; Splevins et al., 2010). This experience may provide the foundation for VPTG and secondary traumatic stress to develop simultaneously, contributing to the positive association reported between the two phenomena.

However, not all research in this area is consistent. Several studies also reported finding no association between VPTG and secondary traumatic stress (Gibbons et al., 2011; Taubman-BenAri \& Weintroub, 2008), while a third suggested a more complex alternative (Shiri et al., 2008a). Shiri et al. (2008a) reported that the relationship between VPTG and secondary traumatic stress was best explained as curvilinear. Initially, VPTG increased linearly with increases in secondary traumatic stress; however, at a point VPTG reached a plateau and no longer continued to increase despite further increases in secondary traumatic stress (Shiri et al., 2008a). This curvilinear model 
explained the relationship between secondary traumatic stress and VPTG over and above a linear relationship. A curvilinear relationship has also been reported between posttraumatic growth and Posttraumatic Stress Disorder among direct trauma survivors (e.g., Butler et al., 2005). However, a later study failed to replicate these results (Shiri, et al., 2008b). Further research is needed to ascertain the nature of the relationship between secondary traumatic stress and VPTG, as such research will enable us to better understand the complex and varying ways that health professionals react to vicarious traumatic exposure, and in turn, how to best support them during this time.

\section{Limitations in the literature}

Several limitations were apparent in the literature reviewed. Currently, there is no validated quantitative measure to assess VPTG, and the PTGI is the most commonly used instrument. However, as this review has identified unique elements in the nature of VPTG, the PTGI, and all other measures originally designed to assess posttraumatic growth following direct traumatic exposure, are likely to be limited in their capacity to assess all aspects of VPTG. The assessment of VPTG is further restricted by evidence which suggests that posttraumatic growth scales may be measuring slightly different constructs (Linley et al., 2005).

There are also limitations in the design of the studies reviewed. First, sample sizes were generally small; fewer than half the studies had a sample size exceeding 100 participants. Therefore it is possible that small to moderate effects may have been missed (Linley \& Joesph, 2005; Linley et al., 2005; Samios et al., 2012); this might explain some of the discrepant results reported in this field. Second, there are few longitudinal studies of VPTG, a significant weakness considering that it has been argued posttraumatic growth develops gradually over time (Calhoun \& Tedeschi, 2006; Tedeschi \& Calhoun, 2004). Third, the majority of reviewed studies did not account for participants' own personal trauma. Therefore, the extent to which the posttraumatic growth reported in these studies is representative of VPTG is unknown, as it may have arisen from participants' own personal trauma. Finally, there has been very little research comparing VPTG between several populations. Comparative research may enable us to assess whether some types of professionals are more likely to develop VPTG, identify why this is the case, and in turn use this information to facilitate VPTG among groups that previously did not demonstrate high levels of growth.

The validity of VPTG as a construct was not discussed in any of the articles reviewed. Several issues regarding the validity of the wider posttraumatic growth construct have been raised in the literature, all of which are applicable to VPTG. For example, there has been controversy over whether perceived posttraumatic growth equates to actual change (e.g., Joseph, 2011), or whether posttraumatic growth is "illusory" (Taylor, 1983; Taylor \& Armor, 1996). Future research should aim to explore these validity issues within the context of VPTG.

Finally, while reviewing the selected articles, it was evident that there is a high degree of inconsistency among results in this field. This makes it is difficult to draw conclusions and to outline meaningful implications for health professionals working with trauma survivors. In particular, results were very mixed regarding whether certain psychological, behavioural, and external factors facilitated VPTG, and how VPTG is related to secondary traumatic stress.

\section{Directions for future research}

With so much literature focusing on the negative impact of working with trauma survivors, it is important that adequate attention is also paid to the positive consequences of such work. Future research investigating factors that enhance the development of VPTG could inform professionals 
on how to best prepare themselves for trauma work, and could have implications regarding how health care organisations can best support their employees and facilitate VPTG in the workplace. Future research should work to overcome limitations in the field by producing a validated instrument that specifically aims to measure VPTG. This instrument should be informed by theoretical and empirical literature and should consider elements general to the posttraumatic growth construct and specific to VPTG. Finally, research that aims to provide a greater understanding of the complex relationship between VPTG and secondary traumatic stress would be useful.

\section{Limitations of the current review}

First, only journal articles printed in English were eligible for inclusion in this review. It is possible that valuable contributions to this field have been printed in another language or exist in other forms of text, such as books, dissertations, or theses. In addition, valuable articles may have fallen outside the databases utilised in the current study. While care was taken to perform searches on a variety of databases that were deemed most likely to yield relevant results, it is possible that articles have been missed. Therefore, while this review provides the most comprehensive review of the VPTG literature to date, it cannot be said to be all-inclusive.

Second, the inclusion criteria for this review required studies to have a specific aim of studying VPTG. Studies that captured the benefits of trauma work without a specific focus on VPTG (e.g., Steed \& Downing, 1998) were not eligible for inclusion. The specified criterion was established to capture a homogenous body of research from which meaningful conclusions could be drawn. However, this once again limits the research reviewed and means that studies may have been missed that would have contributed significantly to the results provided here.

Third, studies that reported participants to have a "shared trauma reality" with direct trauma survivors (e.g., Tosone, 2011) were not included in this review, as the review was specific to vicarious traumatic exposure. That is not to say that the studies failed to investigate a form of posttraumatic growth worth attention. It may be that the individuals included in these studies exhibit a form of growth that matches VPTG, or they may demonstrate their own unique manifestation. Inclusion of these studies may have altered the results presented in this review. Future research could compare such studies with those focusing exclusively on VPTG to ascertain similarities and differences between these two populations.

\section{Summary}

This review aimed to provide a comprehensive review of the VPTG literature with five focal areas: assessment, the level of similarity between VPTG and direct posttraumatic growth, facilitating factors, the relationship between VPTG and secondary traumatic stress, and limitations. A review of the assessment procedures found quantitative literature to be limited in its capacity to measure VPTG, due to the absence of a scale designed specifically for vicarious traumatic exposure. VPTG was found to be partially distinct from direct posttraumatic growth; subtle differences included a more abstract form of growth and professional enhancement was found to be a unique manifestation of change. Participants' VPTG was facilitated by a range of cognitive, psychological, behavioural, interpersonal and external factors; however, it should be noted that there was a great deal of inconsistency in the results. Regarding the relationship between VPTG and secondary traumatic stress, three possible explanations have been proposed: a positive linear relationship, no relationship, and a curvilinear relationship. Future research is needed to ascertain which of these three possibilities best explains the association between VPTG and secondary traumatic stress. Current limitations of the literature include a lack of appropriate 
measures, longitudinal research, and consideration of validity; discrepant results; small sample sizes; and the failure to account for personal trauma history. These limitations represent areas in need of future research.

\section{Authors}

Shekinah Manning-Jones

Massey University

shekinahmanningjones@gmail.com

Ian de Terte

Massey University

Christine Stephens

Massey University

\section{Publishing Timeline}

Received 9 June 2014

Accepted 27 March 2015

Published 21 June 2015

\section{References}

Arnold, D., Calhoun, L. G., Tedeschi, R., \& Cann, A. (2005). Vicarious posttraumatic growth in psychotherapy. Journal of Humanistic Psychology, 45, 239-263. http://dx.doi.org/10.1177/0022167805274729

Barrington, A. G., \& Shakespeare-Finch, J. (2013). Working with refugee survivors of torture and trauma: An opportunity for vicarious post-traumatic growth. Counselling Psychology Quarterly, 26(1), 89-105. http://dx.doi.org/10.1080/09515070.2012.727553

Ben-Porat, A., \& Itzhaky, H. (2009). Implications of treating family violence for the therapist: Secondary traumatization, vicarious traumatization, and growth. Journal of Family Violence, 24, 507-515. http://dx.doi.org/10.1007/s10896-009-9249-0

Bentar, M. (2000). A qualitative study of the effect of a history of childhood sexual abuse on therapists who treat survivors of sexual abuse. Journal of Trauma \& Dissociation, 1(3), 9-28. http://dx.doi.org/10.1300/J229v01n03 02

Brockhouse, R., Msetfi, R. M., Cohen, K., \& Joseph, S. (2011). Vicarious exposure to trauma and growth in therapists: The moderating effects of sense of coherence, organizational support, and empathy. Journal of Traumatic Stress, 24(6), 735-742. http://dx.doi.org/10.1002/jts.20704

Butler, L. D., Blasey, C. M., Garlan, R. W., McMaslin, S. E., Azarow, J., Chen, X., . . Spiegel, D. (2005). Posttraumatic growth following the terrorist attacks of September 11, 2001; Cognitive, coping, and trauma symptom predictors in an internet convenience sample. Traumatology, 11(4), 247-267. http://dx.doi.org/10.1177/153476560501100405

Calhoun, L. G., \& Tedeschi, R. G. (2006). The handbook of posttraumatic growth: Research and practice. London: Lawrence Erlbaum.

Canfield, J. (2005). Secondary traumatization, burnout, and vicarious traumatization: A review of the literature as it relates to therapists who treat trauma. Smith College Studies in Social Work, 75(2), 81101. http://dx.doi.org/10.1300/J497v75n02 06

Carmel, S. (1997). The professional self-esteem of physicians scale, structure, properties and the relationship to work outcomes and life satisfaction. Psychological Reports, 80(2), 591-602. http://dx.doi.org/10.2466/pr0.1997.80.2.5911

Cohen, K., \& Collens, P. (2013). The impact of trauma work on trauma workers: A metasynthesis on vicarious trauma and vicarious posttraumatic growth. Psychological Trauma: Theory, Research, Practice, and Policy, 5(6), 570-580. http://dx.doi.org/10.1037/a0030388 
Davis, C. G., \& Macdonald, S. L. (2004). Threat appraisals, distress and the development of positive life changes after September 11th in a Canadian sample. Cognitive Behaviour Therapy, 33(2), 68-78. http://dx.doi.org/10.1080/16506070410025832

Gibbons, S., Murphy, D., \& Joseph, S. (2011). Countertransference and positive growth in social workers. Journal of Social Work Practice, 25(1), 17-30. http://dx.doi.org/10.1080/02650530903579246

Guhan, R., \& Leibling-Kalifani, H. (2011). The experiences of staff working with refugees and asylum seekers in the United Kingdom: A grounded theory exploration. Journal of Immigrant E Refugee Studies, 9(3), 205-228. http://dx.doi.org/10.1080/15562948.2011.592804

Hefferon, K., Grealy, M., \& Mutrie, N. (2009). Posttraumatic growth and life threatening physical illness: A systematic review of the qualitative literature. British Journal of Health Psychology, 14(2), 343-378. http://dx.doi.org/10.1348/135910708X332936

Hyatt-Burkhart. (2014). The experience of vicarious posttraumatic growth in mental health workers. Journal of Loss and Trauma: International Perspectives on Stress E Coping, 19(5), 452-461. http://dx.doi.org/10.1080/15325024.2013.797268

Joseph, S. (2011). What doesn't kill us. The new psychology of posttraumatic growth. New York, NY: Basic Books.

Joseph, S., Williams, R., \& Yule, W. (1993). Changes in outlook following disaster: The preliminary development of a measure to assess positive and negative responses. Journal of Traumatic Stress, 6(2), 271-279. http://dx.doi.org/10.1002/jts.2490060209

Kjellenberg, E., Nilsson, F., Daukantaité, D., \& Cardeña, E. (2014). Transformative narratives: The impact of working with war and torture survivors. Psychological Trauma: Theory, Research, Practice, and Policy, 6(2), 120-128. http://dx.doi.org/10.1037/a0031966

Lambert, F., \& Lawson, G. (2013). Resilience of professional counselors following Hurricanes Katrina and Rita. Journal of Counseling $\mathcal{E}$ Development, 91, 261-268. http://dx.doi.org/10.1002/j.1556$\underline{6676.2013 .00094 . x}$

Lelorain, S., Bonnaud-Antiqnac, A., \& Florin, A. (2010). Long term posttraumatic growth after breast cancer: Prevalence, predictors and relationships with psychological health. Journal of Clinical Psychology in Medical Settings, 17(1), 14-22. http://dx.doi.org/10.1007/s10880-009-9183-6

Linley, P. A., \& Joseph, S. (2005). Positive and negative changes following occupational death exposure. Journal of Traumatic Stress, 18(6), 751-758. http://dx.doi.org/10.1002/jts.20083

Linley, P. A., \& Joseph, S. (2007). Therapy work and therapists' positive and negative well-being. Journal of Social and Clinical Psychology, 385-403. http://dx.doi.org/10.1521/jscp.2007.26.3.385

Linley, P. A., Joseph, S., \& Loumidis, K. (2005). Trauma work, sense of coherence, and positive and negative changes in therapists. Psychotherapy and Psychosomatics, 75(3), 185-188. http://dx.doi.org/10.1159/000084004

Linley, P. A., Joseph, S., Cooper, R., Harris, S., \& Meyer, C. (2003). Positive and negative changes following vicarious exposure to the September 11 terrorist attacks. Journal of Traumatic Stress, 16(5), 481-485. http://dx.doi.org/10.1023/A:1025710528209

McMillen, J. C., \& Fisher, R. H. (1998). The Perceived Benefit Scales: Measuring perceived positive life changes after negative events. Social Work Research, 22, 173-187. http://dx.doi.org/10.1093/swr/22.3.173

Mols, F., Vingerhoets, A. J., Coebergh, J. W., \& van de Poll-Franse, L. V. (2009). Well-being, posttraumatic growth and benefit finding in long-term breast cancer survivors. Psychology $\mathcal{E}$ Health, 24(5), 583-595. http://dx.doi.org/10.1080/08870440701671362

O'Sullivan, J., \& Whelan, T. A. (2011). Adversarial growth in telephone counsellors: Psychological and environmental influences. British Journal of Guidance E Counselling, 39(4), 307-323. http://dx.doi.org/10.1080/03069885.2011.567326

Samios, C., Rodzik, A. K., \& Abel, L. M. (2012). Secondary traumatic stress and adjustment in therapists who work with sexual violence survivors: The moderating role of posttraumatic growth. British Journal of Guidance E Counselling, 40(4), 341-356. http://dx.doi.org/10.1080/03069885.2012.691463

Satkunanayagam, K., Tunariu, A., \& Tribe, R. (2010). A qualitative exploration of mental health professionals' experience of working with survivors of trauma in Sri Lanka. International Journal of Culture and Mental Health, 3(1), 43-51. http://dx.doi.org/10.1080/17542861003593336 
Schaefer, J. A., \& Moos, R. H. (1998). The context for posttraumatic growth: Life crises, individual and social resources, and coping. In R. G. Tedeschi, C. L. Park, \& L. G. Calhoun (Eds.), Posttraumatic growth: Positive changes in the aftermath of crisis (pp. 99-125). Mahwah, NJ: Lawrence Erlbaum Associates Publishers.

Shamai, M., \& Ron, P. (2009). Helping direct and indirect victims of national terror: Experiences of Israeli social workers. Qualitative Health Research, 19(1), 42-54. http://dx.doi.org/10.1177/1049732308327350

Shiri, S., Wexler, I. D., Alkalay, Y., Meiner, Z., \& Kreitler, S. (2008a). Positive psychological impact of treating victims of politically motivated violence among hospital-based health care providers. Psychotherapy and Psychosomatics, 77, 315-318. http://dx.doi.org/10.1159/000142524

Shiri, S., Wexler, I. D., Alkalay, Y., Meiner, Z., \& Kreitler, S. (2008b). Positive and negative psychological impact after secondary exposure to politically motivated violence among body handlers and rehabilitation workers. Psychotherapy and Psychosomatics, 196(12), 906-911. http://dx.doi.org/10.1097/NMD.0b013e31818ec80b

Shiri, S., Wexler, I. D., \& Kreitler, S. (2010). Cognitive orientation is predictive of posttraumatic growth after secondary exposure to trauma. Traumatology, 16(1), 42-48. http://dx.doi.org/10.1177/1534765609348243

Splevins, K. A., Cohen, K., Joseph, S., Murray, C., \& Bowley, J. (2010). Vicarious posttraumatic growth among interpreters. Qualitative Health Research, 20(12), 1705-1716. http://dx.doi.org/10.1177/1049732310377457

Stamm, B. H. (2005). The ProQOL Manual: The Professional Quality of Life Scale: Compassion Satisfaction, Burnout, and Compassion Fatigue/Secondary Trauma Scales. Baltimore, MD: The Sidran Press.

Steed, L. G., \& Downing, R. (1998). Vicarious traumatisation amongst psychologists and professional counsellors working in the field of sexual abuse/assault. Australasian Journal of Disaster and Trauma Studies, 2(2), 1-9. http://trauma.massey.ac.nz/

Swickert, R., Hittner, J. B., DeRoma, V., \& Saylor, C. (2006). Responses to the September 11, 2001 terrorist attacks: Experience of an indirect traumatic event and its relationship with perceived benefits. The Journal of Psychology, 410(6), 565-577. http://dx.doi.org/10.3200/JRLP.140.6.565-577

Taku, K. (2014). Relationships among perceived psychological growth, resilience and burnout in physicians. Personality and Individual Differences, 59, 120-123. http://dx.doi.org/10.1016/j.paid.2013.11.003

Taubman-Ben-Ari, O., \& Weintroub, A. (2008). Meaning in life and personal growth among pediatric physicians and nurses. Death Studies, 32, 621-645. http://dx.doi.org/10.1080/07481180802215627

Taylor, S. E. (1983). Adjustment to threatening events: A theory of cognitive adaptation. American Psychologist, 38(11), 1161-1173. http://dx.doi.org/10.1037/0003-066X.38.11.1161

Taylor, S. E., \& Armor, D. A. (1996). Positive illusions and coping with adversity. Journal of Personality, 64(4), 873-898. http://dx.doi.org/10.1111/j.1467-6494.1996.tb00947.x

Tedeschi, R. G., \& Calhoun, L. G. (1996). The Posttraumatic Growth Inventory: Measuring the positive legacy of trauma. Journal of Traumatic Stress, 9(3), 455-471. http://dx.doi.org/10.1002/jts.2490090305

Tedeschi, R. G., \& Calhoun, L. G. (2004). Post-traumatic growth: Conceptual foundations and empirical evidence. Psychology Inquiry, 15(1), 1-18. http://dx.doi.org/10.1207/s15327965pli1501 01

Tehrani, N. (2007). The cost of caring - the impact of secondary trauma on assumptions, values and beliefs. Counselling Psychology Quarterly, 20(4), 325-339. http://dx.doi.org/10.1080/09515070701690069

Tehrani, N. (2010). Compassion fatigue: Experiences in occupational health, human resources, counselling and police. Occupational Medicine, 60, 133-138. http://dx.doi.org/10.1093/occmed/kqp174

Tosone, S. (2011). The legacy of September 11: Shared trauma, therapeutic intimacy, and professional posttraumatic growth. Traumatology, 17(3), 25-29. http://dx.doi.org/10.1177/1534765611421963

Wild, N. D., \& Paivio, S. C. (2004). Psychological adjustment, coping, and emotion regulation as predictors of posttraumatic growth. Journal of Aggression, Maltreatment \& Trauma, 8(4), 97-122. http://dx.doi.org/10.1300/J146v08n04 05

Windle, G. (2011). What is resilience? A review and concept analysis. Reviews in Clinical Gerontology, 21, 152-169. http://dx.doi.org/10.1017/S0959259810000420 